https://doi.org/10.11646/zootaxa.4455.1.8

http://zoobank.org/urn:lsid:zoobank.org:pub:9BD2FDD3-3A77-4F54-B0D1-16A558F93CBD

\title{
A new species of Cryptoperla Needham, 1909 (Plecoptera: Peltoperlidae) from Guangxi of China, based on male, female, and larval stage
}

\author{
WEIHAI LI ${ }^{1,3}$ \& DÁVID MURÁNYI ${ }^{2,3}$ \\ ${ }^{1}$ Department of Plant Protection, Henan Institute of Science and Technology, Xinxiang, Henan, 453003 China. \\ E-mail:lwh7969@163.com \\ ${ }^{2}$ Plant Protection Institute, Centre for Agricultural Research, Hungarian Academy of Sciences, Herman Ottó út 15, Budapest H-1022, \\ Hungary, and Department of Zoology, Hungarian Natural History Museum, Baross u. 13, Budapest H-1088, Hungary. \\ E-mail:d.muranyi@gmail.com,muranyi.david@agrar.mta.hu,muranyi.david@nhmus.hu \\ ${ }^{3}$ Corresponding authors
}

\begin{abstract}
Cryptoperla teana sp. n. is described from male and female adults, larvae, and exuviae collected on the plateau of the Daming Mountains, Guangxi Zhuang Autonomous Region, of southern China. The present discovery represents the first record of the family Peltoperlidae in Guangxi. The distribution of its congeners is illustrated on a map.
\end{abstract}

Key words: Cryptoperla teana sp. n., Damingshan, Oriental Region, distribution

\section{Introduction}

Peltoperlidae is a small family of systellognathan Plecoptera distributed in the Nearctic, Oriental, and East Palaearctic region (DeWalt et al. 2018). The monotypic Microperlinae is restricted to China and Japan, whereas Peltoperlinae is distributed over most of Asia and North America. Three genera of the Peltoperlinae are endemic to Asia, while Yoraperla Ricker, 1952 and Soliperla Ricker, 1952 occur on both continents (Stark \& Sivec 2007a, Huo et al. 2017). The genus Cryptoperla Needham, 1909 is the far most speciose genus of the family, with 30 valid species amongst 10 that are known from mainland China. Most of these are found in the Oriental region but enter also the Palaearctic in Japan (Stark \& Sivec 2007a, 2007b).

During March of 2015, we took a collecting expedition to central and southwestern areas of Guangxi Zhuang Autonomous Region of southern China. Some of the results of our trip have been previously already published (Li et al. 2017a, b, Kontschán et al. 2015) but descriptions of several further stoneflies are still in progress. Herein, we report the only Peltoperlidae collected on the Damingshan Plateau that proved to be a new species and the first record of the family from Guangxi. In addition, we present a map on the previous published records for the genus.

\section{Material and methods}

Larvae and exuviae were collected by aquatic net and searching under stones along the edge of seeps and streams. Adults were reared from larvae kept alive between moss and moist leaves in plastic tubes. Types are deposited in the Insect Collection of Henan Institute of Science and Technology (HIST), Xinxiang, China and the Collection of Smaller Insect Orders, Department of Zoology, Hungarian Natural History Museum (HNHM), Budapest, Hungary, respectively, as indicated in the text. Types were preserved in $75 \%$ ethanol. Illustrations were made with the aid of a Leica S8APO and a Nikon SMZ1500 microscope, further colour illustrations were made with the aid of Imaging Source CCD attached to Leica M420 microscope. Morphological terminology primarily follows that of Stark \& $\operatorname{Sivec}(2007 a)$. 
Distribution data were compiled from the following papers: Banks (1938, 1940), Du \& Sivec (2005), Huo \& Du (2018), Kato et al. (2013), Kawai (1968a, 1968b), Klapálek (1913), Maruyama (2002), Needham (1909), Okamoto (1912), Sivec (1995, 2005), Stark (1989), Stark \& Sivec (2007a, 2007b), Uchida \& Isobe (1988), Wu (1973), Wu \& Claassen (1934), Zwick (1977), Zwick \& Sivec (1980).

\section{Results}

Cryptoperla teana Li \& Murányi, sp.n.

(Figs. 1-40)

Type materials: Holotype male (HIST), China: Guangxi Zhuang Autonomous Region, Wuming County, Damingshan National Natural Reserve, seep at Golden Turtle Waterfall, $1150 \mathrm{~m}, 23^{\circ} 30.373^{\prime} \mathrm{N}, 108^{\circ} 26.141^{\prime} \mathrm{E}$, 2015.III.21, leg. J. Kontschán, J.Y. Li, S. Li, W.H. Li, D. Murányi, G.Q. Wang. Paratypes: same locality and date: 1 female and its exuviae (HNHM: No. PLO54); Damingshan National Natural Reserve, inflow stream above Dragon Lake, 1225 m, 2329.751'N, 108²6.242'E, 2015.III.22, leg. J. Kontschán, J.Y. Li, S. Li, W.H. Li, D. Murányi, G.Q. Wang.: 15 larvae, 2 exuviae (HNHM: No. PLO60).

Adult. General body color light brown with yellow pattern. Biocellate, distance between ocelli about two times the diameter of the ocellus. Head mostly brown but with distinct pale patches around ocelli in dorsal view, and a pale crossbar continuing medially to clypeus on the downcurved apex of head, as seen in frontal view (Figs. 1-2, 18-19). Occipital suture indistinct, occipital rugosities scarce and barely seen; compound eyes black and hairy, antennae brown, mouthparts and palpi pale. Pronotum brown with distinct pale rugosities (Figs. 1, 19). Mesonotum and metanotum ventrally pale with paired longitudinal brown patches laterally, scutum chocolate brown; metathoracal postscutellum with pale, worm-like paired mediolateral process dotted by short, sensilla-like setae (Fig. 20). Wing membrane brownish, veins dark brown; femora and tibiae pale brown, tarsi dark. Abdominal segments mostly pale brown to yellowish.

Male. Forewing length ca. $11.8 \mathrm{~mm}$, body length ca. $9 \mathrm{~mm}$. Terminal 3 segments with brownish terga and distinct lateral marking (Figs. 3-5), posterior half of tergum 10 downcurved (Fig. 9), and the margin parabolic in rear view (Fig. 9). Basal cercal segment ca. $5 \mathrm{X}$ long as basal with and distal half with reddish brown dense, spurlike hair fringe along inner margin, longest hair ca. $2 \mathrm{X}$ long as the cercal width (Figs. 3, 7-8, 11, 13, 15); cercal spur absent. Vesicle of sternum 9 ca. 0.6X long as wide, apex with an interrupted row of long hairs (Fig. 6). Aedeagus (Figs. 10-14, 16-17): basoventrally with conical lower lobe at each lateral corner with slightly coarse surface (Figs. 12-14, 17), the corresponding dorsal part forming a transverse band with rough surface with wrinkles, the posterolateral margin angled (Figs. 10-11, 16); main upper lobe much larger and spherical, without macrosetae (Figs. 11-13).

Female: Forewing length $13 \mathrm{~mm}$, body length $10 \mathrm{~mm}$; habitus and coloration similar to male. Sternum 8 with trapezoid anterior portion subdivided from the large subgenital plate; subgenital plate is broadly rounded, covers most of sternum 9, yellowish and covered by dense but short and thin setae (Fig. 21). Sternum 9 with posteromedial portion subdivided from the basal and lateral portions, white and bald; it is slightly produced posteriorly, fully covers sternum 10. Tergum 10 broadly triangular, darker than the previous terga and sterna, well overhangs paraprocts (Figs. 21-22). Paraprocts and cerci dark brown, unmodified.

Egg: unknown.

Larva. Body length of the female exuviae from Golden Turtle Waterfall $10 \mathrm{~mm}$, larvae and exuviae from Dragon Lake smaller, 8-9 mm, female exuviae 17-18.5 mm. General color greyish dark brown, with distinct yellow and reddish patches (Figs. 24, 38 - Fig. 38 shows alive larva, Fig. 24 made on the basis of exuviae of the same specimen). Coloration of larvae from Dragon Lake less contrasting (Fig. 39). Head with yellow or pale brown occiput, brown anterior to ocelli mouthparts pale, antennae yellowish pale brown. Lacinia bidentate, teeth of equal length, marginal fringe with very long setae; galea shorter than apical tooth of lacinia, bear apical tuft of short setae (Figs. 33-34). Mandible with two molar and three incisor dens, molar well developed (Fig. 35). Pronotum brown with pale, marmorated pattern, following thoracal plates similar but with distinct yellow bars delimiting wing pads; ventral surface of thorax pale. Legs brown with distinct yellow dorsoapical patches on femora, tarsi reddish brown. Abdomen with conspicuous, wide medial yellow marking on the first three terga, following two or three terga are with paired lateral yellowish spots, terminal segments with indistinct pattern; ventral surface uniformly pale. Cerci pale brown, bit darker than antennae. 


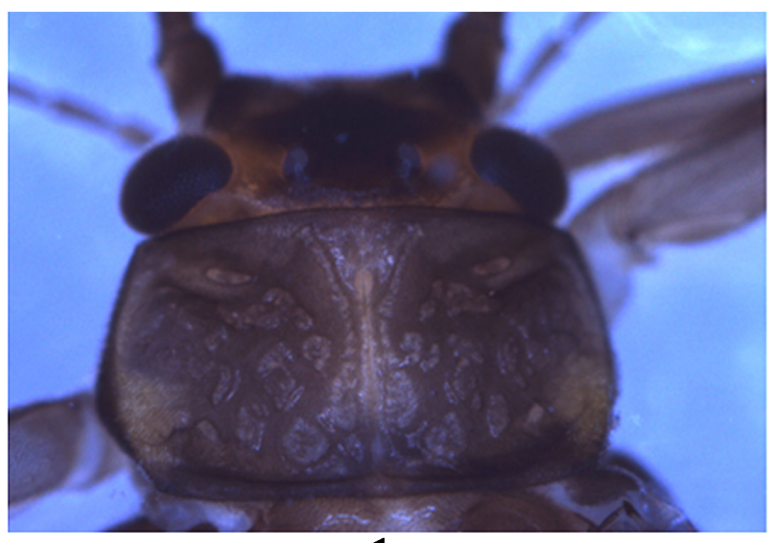

1

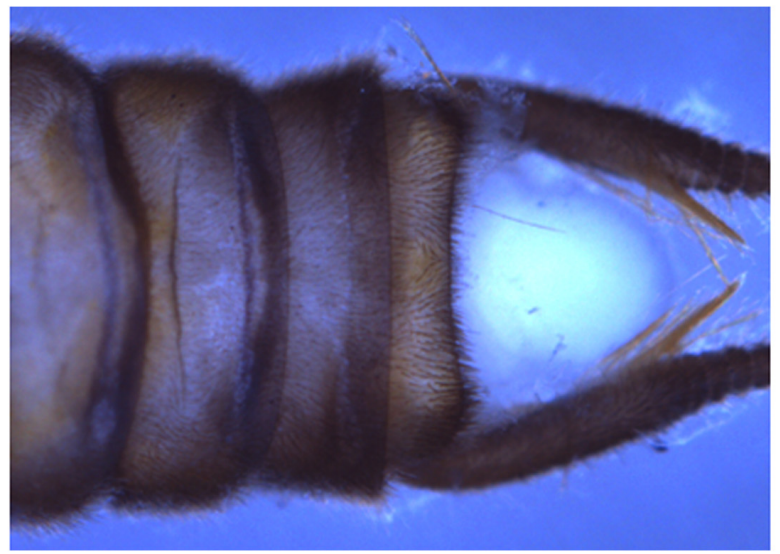

3

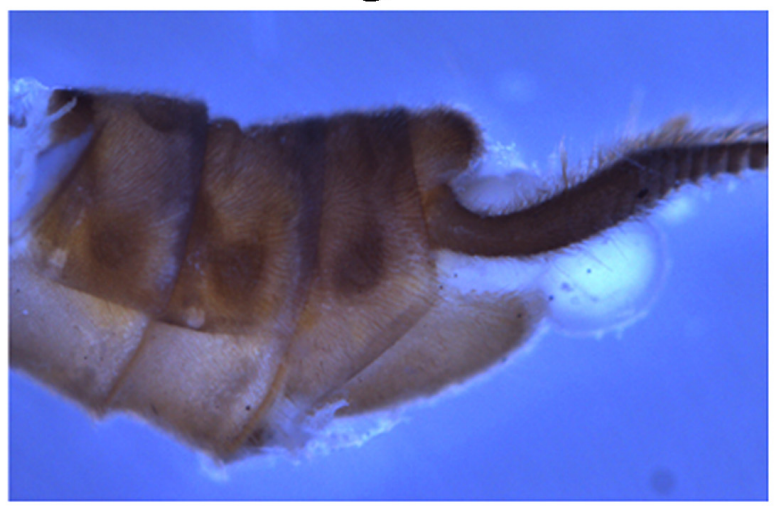

5

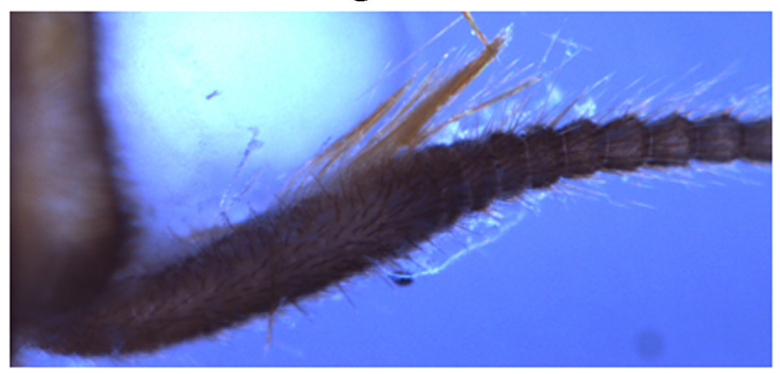

7

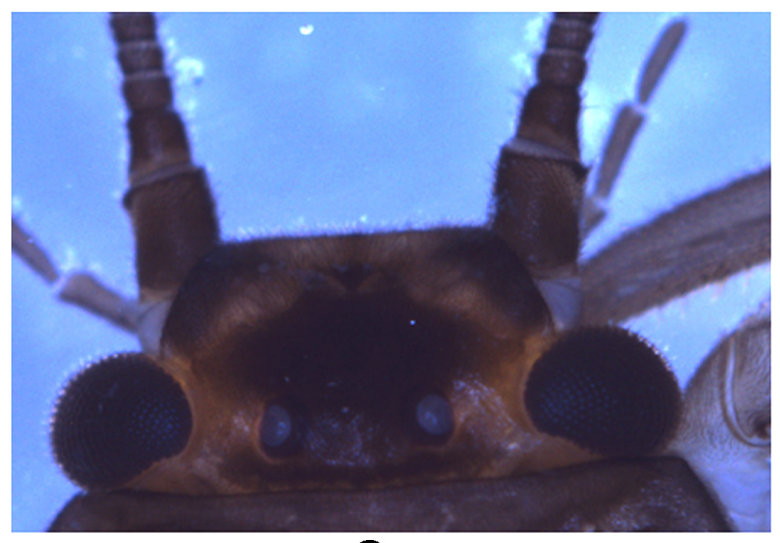

2

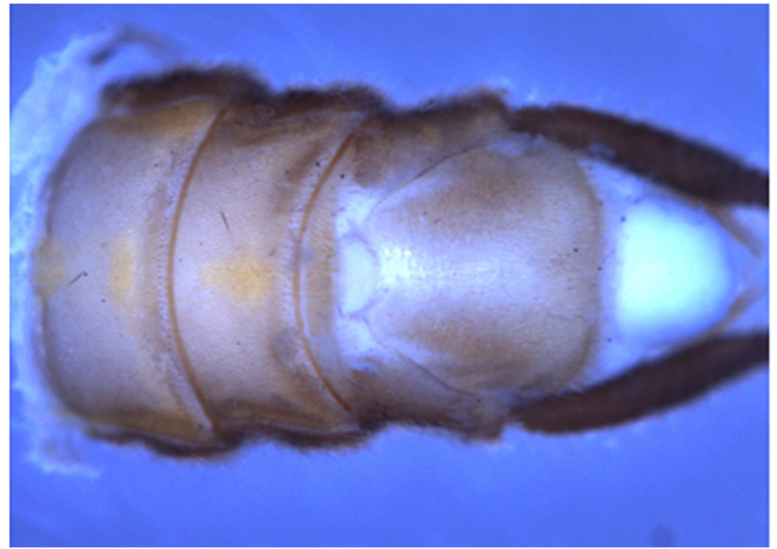

4

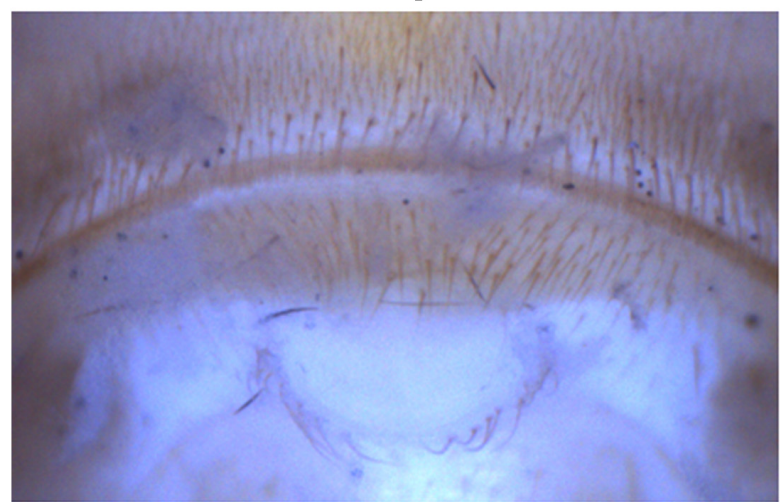

6

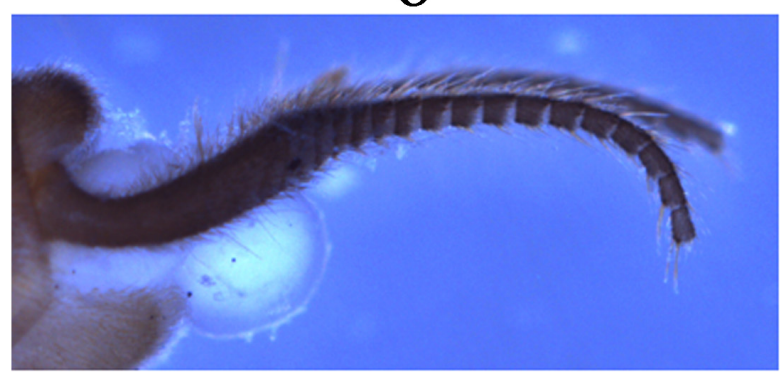

8

FIGURES 1-8. Cryptoperla teana Li \& Murányi, sp. n., holotype male.-1: head and pronotum, dorsal view; 2: head, dorsal view; 3: terminalia, dorsal view; 4: terminalia, ventral view; 5: terminalia, lateral view; 6: vesicle, ventral view; 7: basal half of cercus, dorsal view; 8 : apical segments of cercus, lateral view. 


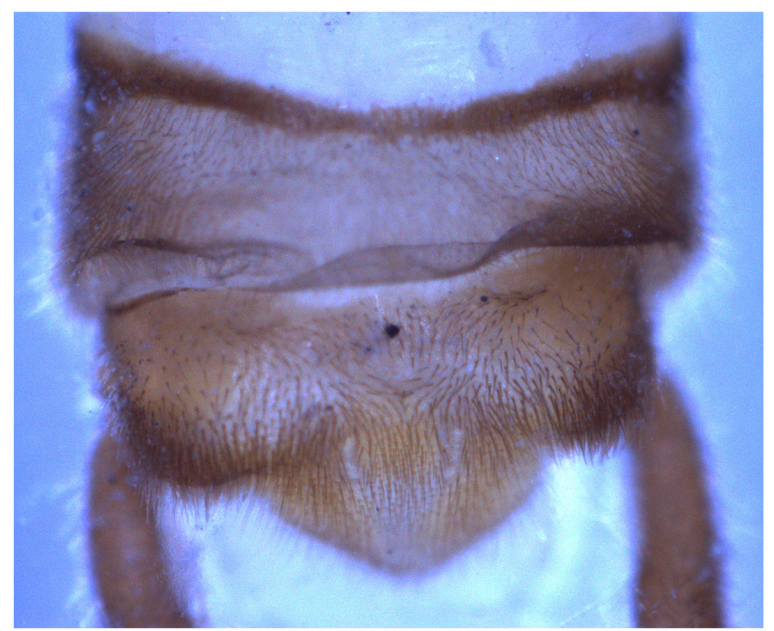

9

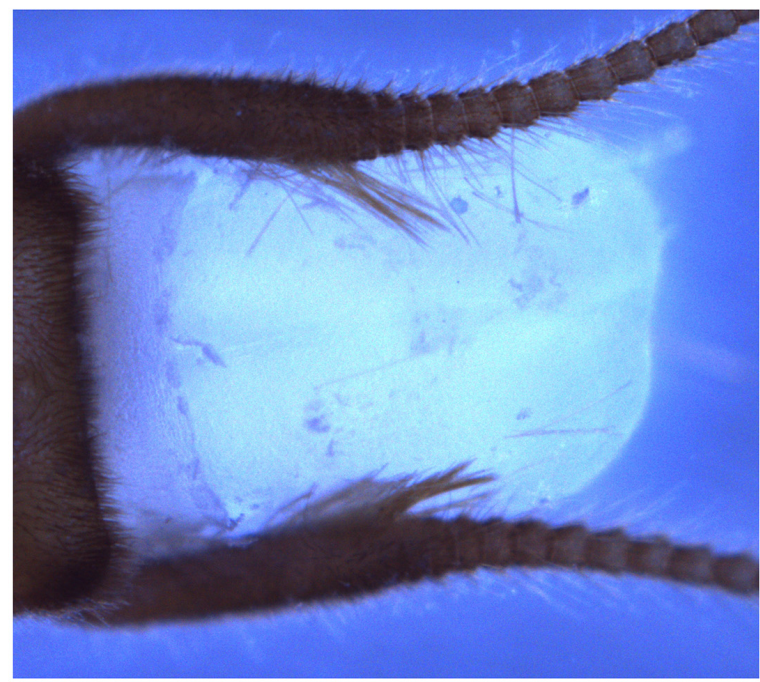

11

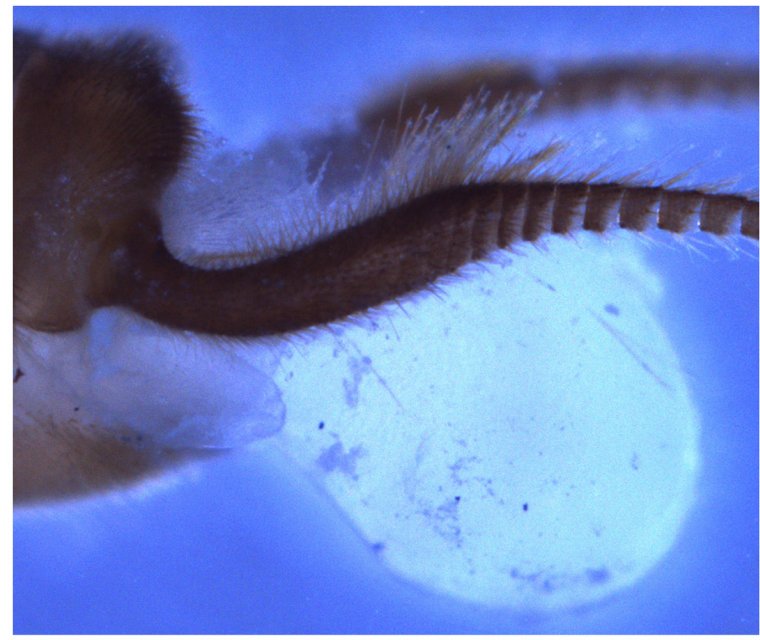

13

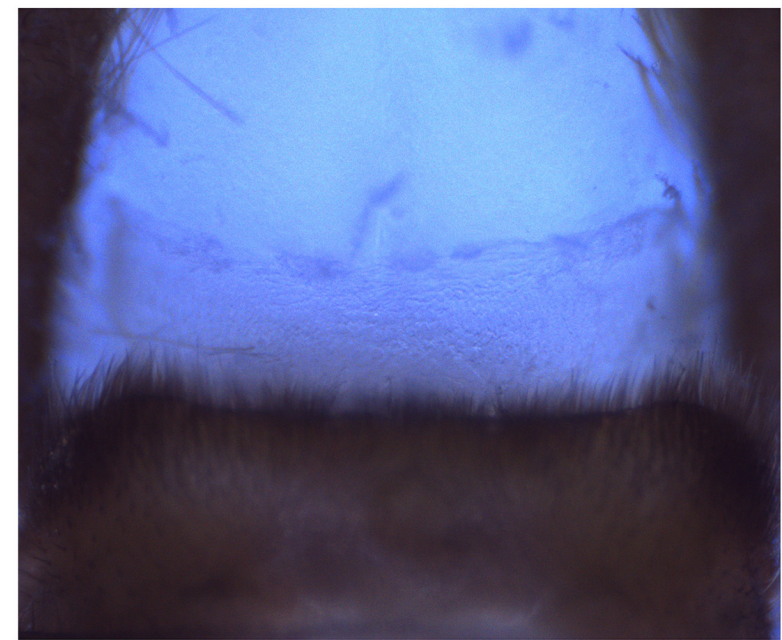

10

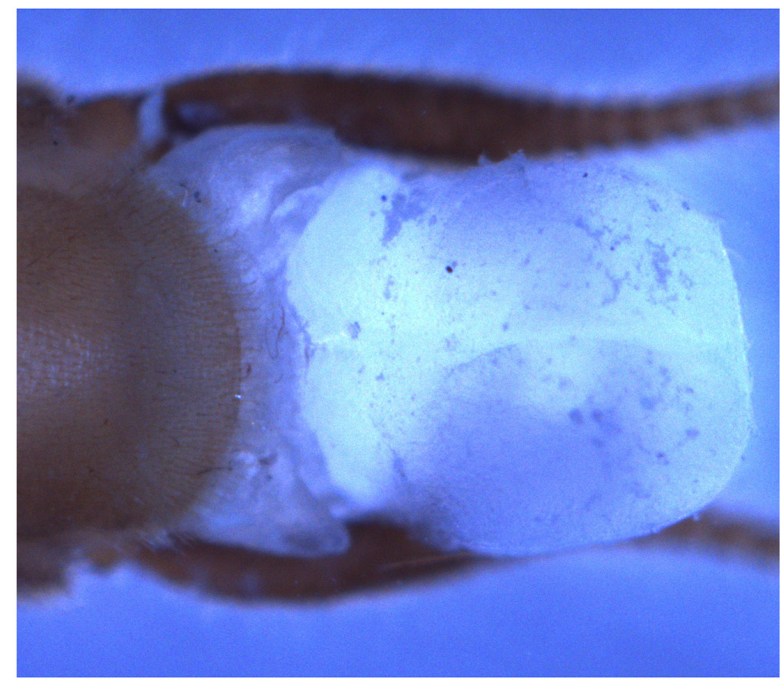

12

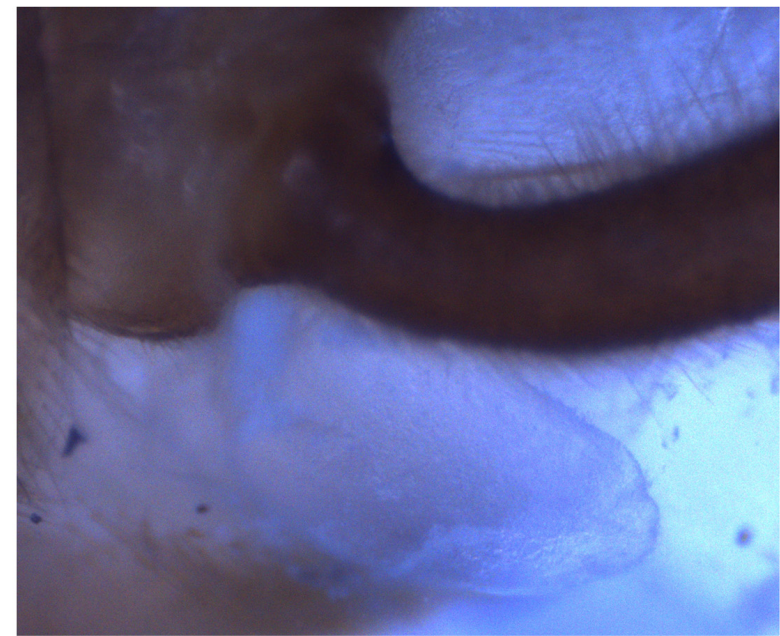

14

FIGURES 9-14. Cryptoperla teana Li \& Murányi, sp. n., holotype male.-9: relaxed tergum 10, dorsal view; 10: basal part of aedeagus, dorsal view; 11: aedeagus, dorsal view; 12: aedeagus, ventral view; 13: aedeagus, lateral view; 14: basoventral lobe of aedeagus, lateral view. 


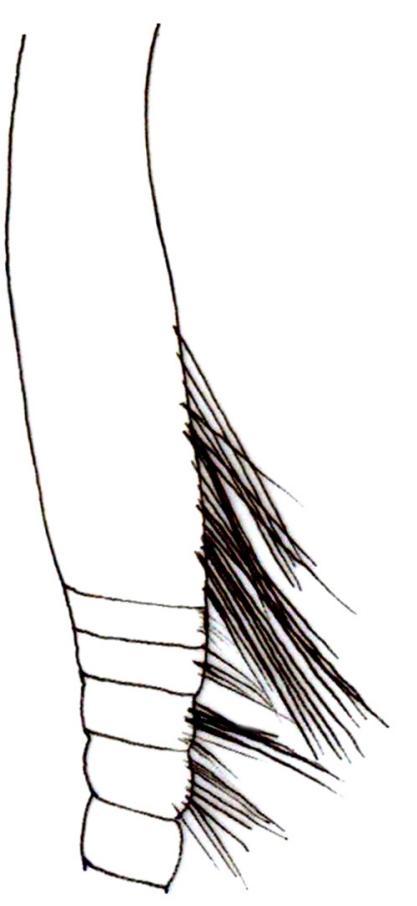

15

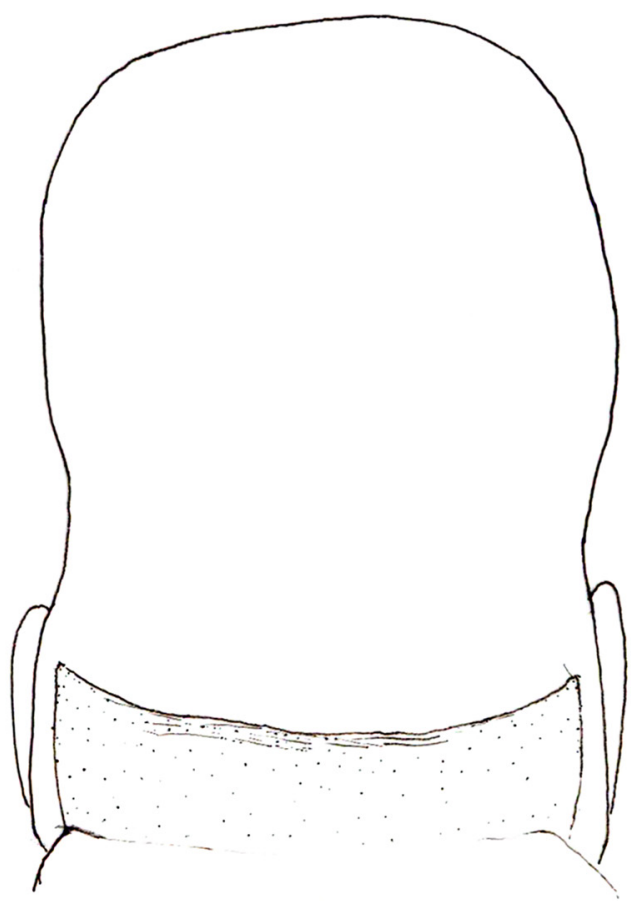

16

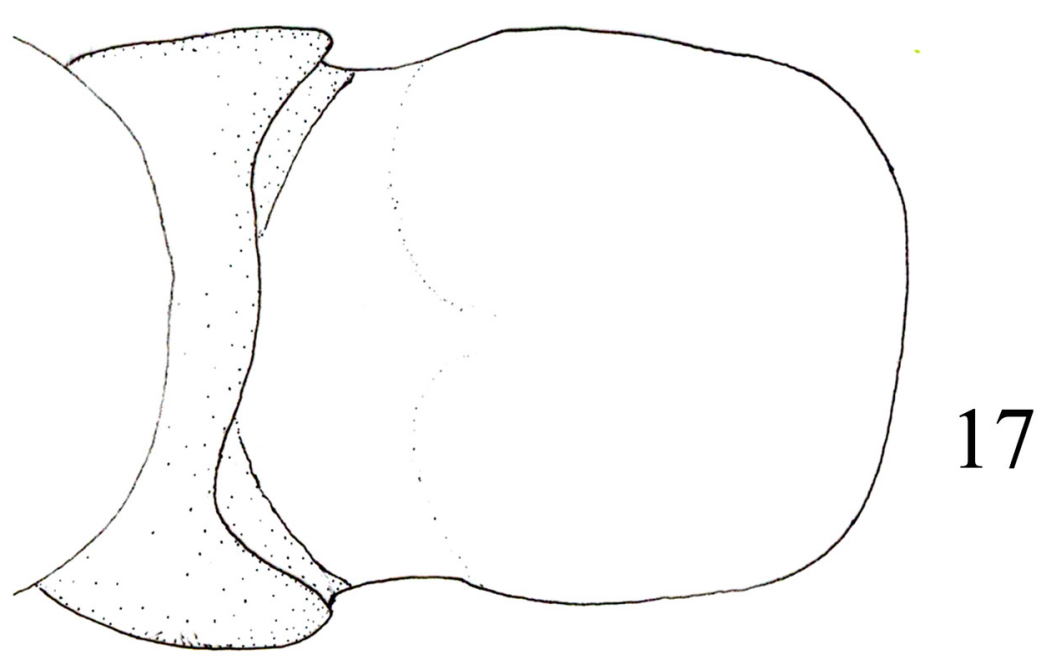

FIGURES 15-17. Cryptoperla teana Li \& Murányi, sp. n., holotype male.-15: basal half of cercus, dorsal view; 16: aedeagus, dorsal view; 17: aedeagus, ventral view.

Meso- and metathoracal posterior supracoxal gills simple, elongated and acute (Figs. 29-30). Paraprocts continued in elongated triangular gills, posteriomedial gill of tergum 10 distinct and elongated (Fig. 28). Ventral setal fringes of thorax consist of complete anterior fringe and well developed posteriolateral fringes on prothorax; mediolateral and well developed poteriolateral fringes on mesothorax; well-developed mediolateral fringes and complete posterior fringe on metathorax (Fig. 23). Legs with dorsal row of swimming hairs scarce and indistinct on femora, more developed on tibiae; clothing hairs black. All abdominal sterna are with complete posterior setal fringe of long, blunt setae (Fig. 26); clothing hairs pale. Posterior setal fringe on abdominal terga consist of five to six short, clavate setae altered with long, acute setae (Fig. 25); clothing hairs black. Posterior fringe of tergum 10 lacks clavate setae but fully armed with long, acute setae. Paraprocts are with pale clothing hairs and a posterior 
fringe of long, blunt setae at the origin of gills (Fig. 27). Basal segments of cerci bear distinct ventral blade-like setae in apical whorls, and dense, long intercalary hairs (Fig. 31); blade-like setae gradually weakens towards the medial portion of the cerci, apical segments are armed only with moderately long setae in apical whorls, and dense, long hairs (Fig. 32).

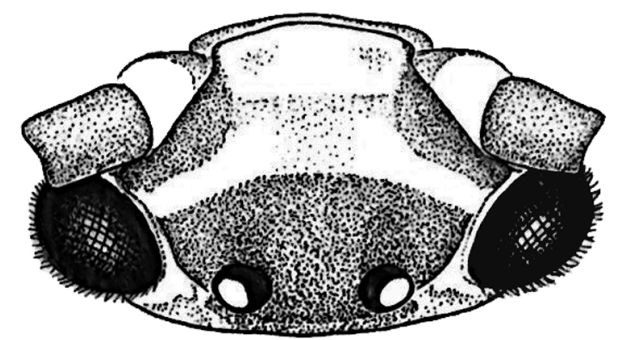

18
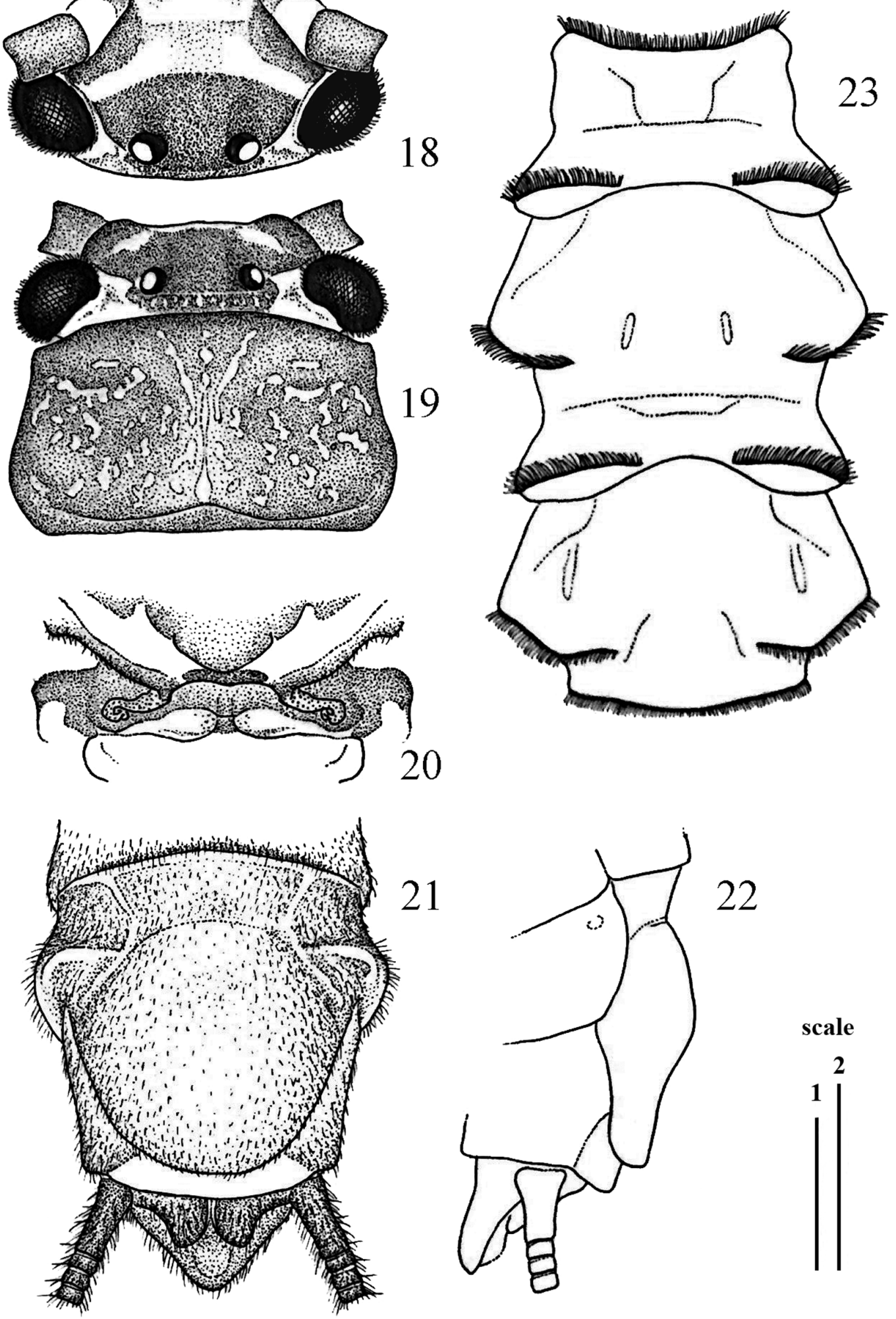

FIGURES 18-23. Cryptoperla teana Li \& Murányi, sp. n., paratype female and its exuviae.-18: head, frontal view; 19: head and pronotum, dorsal view; 20: metathoracal postscutellum, dorsal view; 21: terminalia, ventral view; 22: terminalia, lateral view; 23: thorax of the exuviae, ventral view_scales $1 \mathrm{~mm}$; scale 1 for Fig. 23, scale 2 for Figs 18-22. 


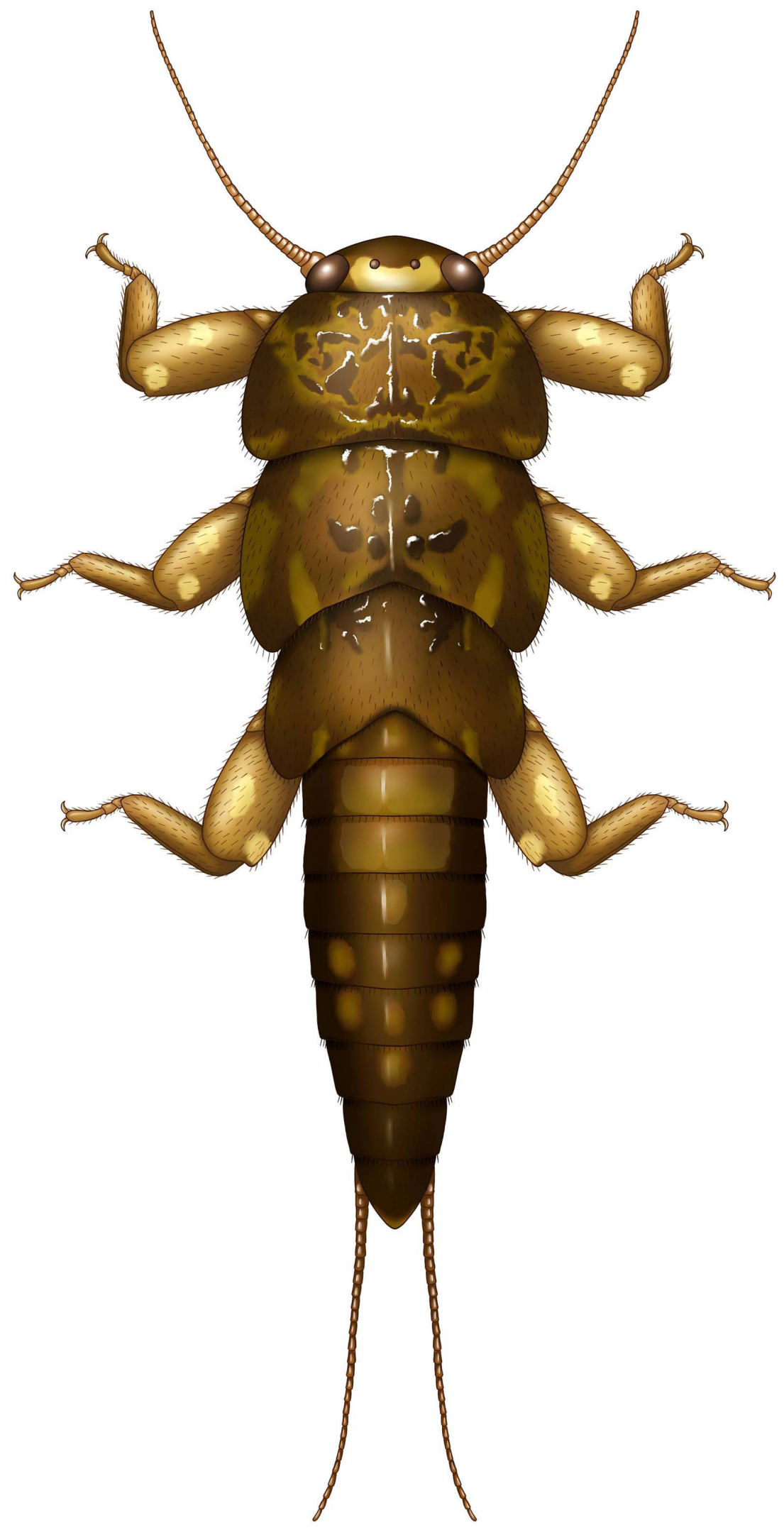

FIGURE 24. Cryptoperla teana Li \& Murányi, sp. n., habitus of paratype larva; showing color pattern of pharate larva from which the paratype emerged, note that it is the same specimen as in fig. 38, not in fig. 39 showing the color patter of last instar larva from another locality. 

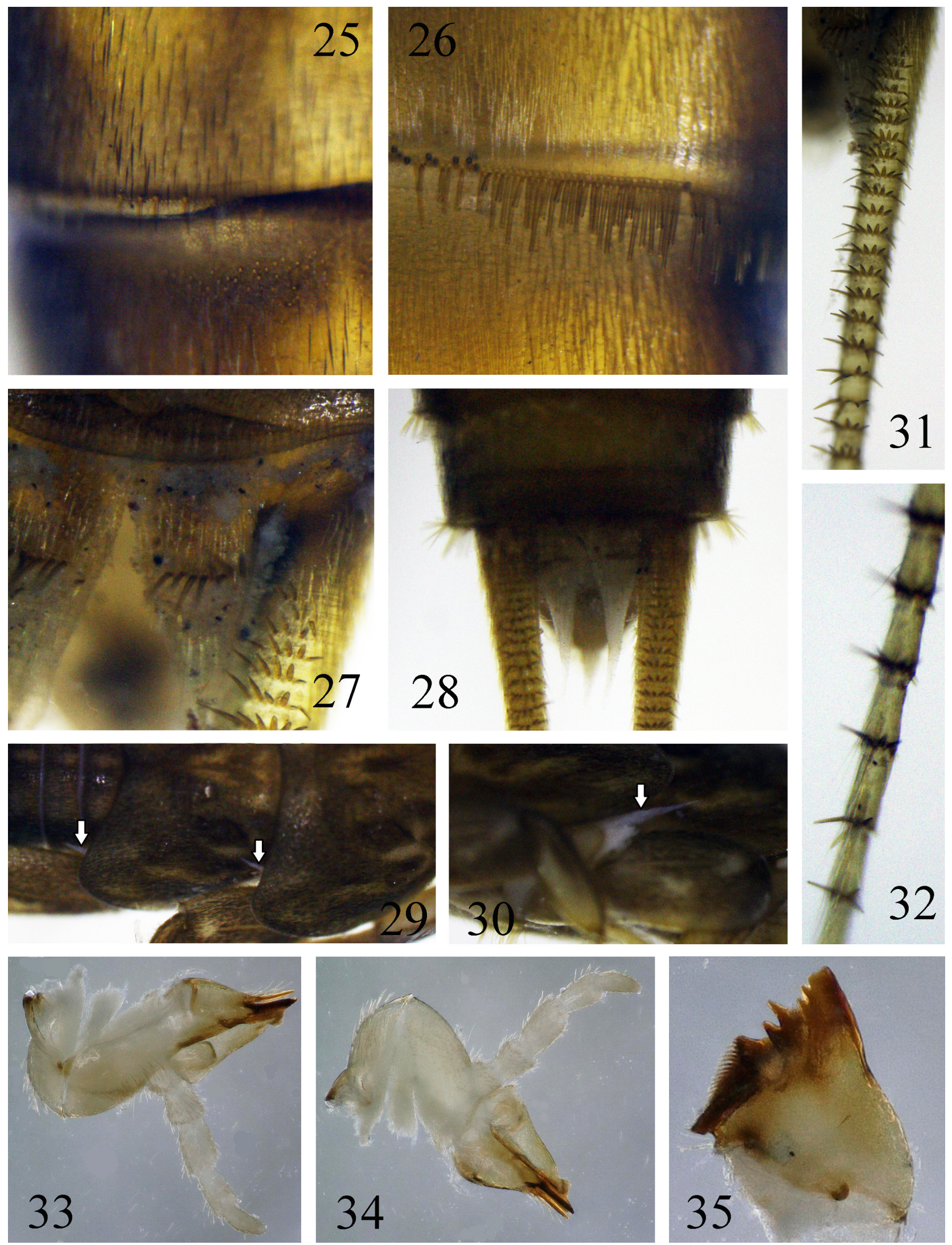

FIGURES 25-35. Cryptoperla teana Li \& Murányi, sp. n., paratype larvae and exuviae.-25: terga 5-6, dorsal view; 26: sterna 5-6, ventral view; 27: paraprocts and base of cercus, ventral view; 28: terminalia, ventral view; 29: meso-and metathorax, dorsolateral view; 30: mesothorax, lateral view; 31: basal half of cercus, ventral view; 32: apical segments of cercus, ventral view; 33: left maxilla, ventral view; 34: left maxilla, dorsal view; 35: left mandible, ventral view—not to scale; arrows on Figs. 29-30 indicate gills. 

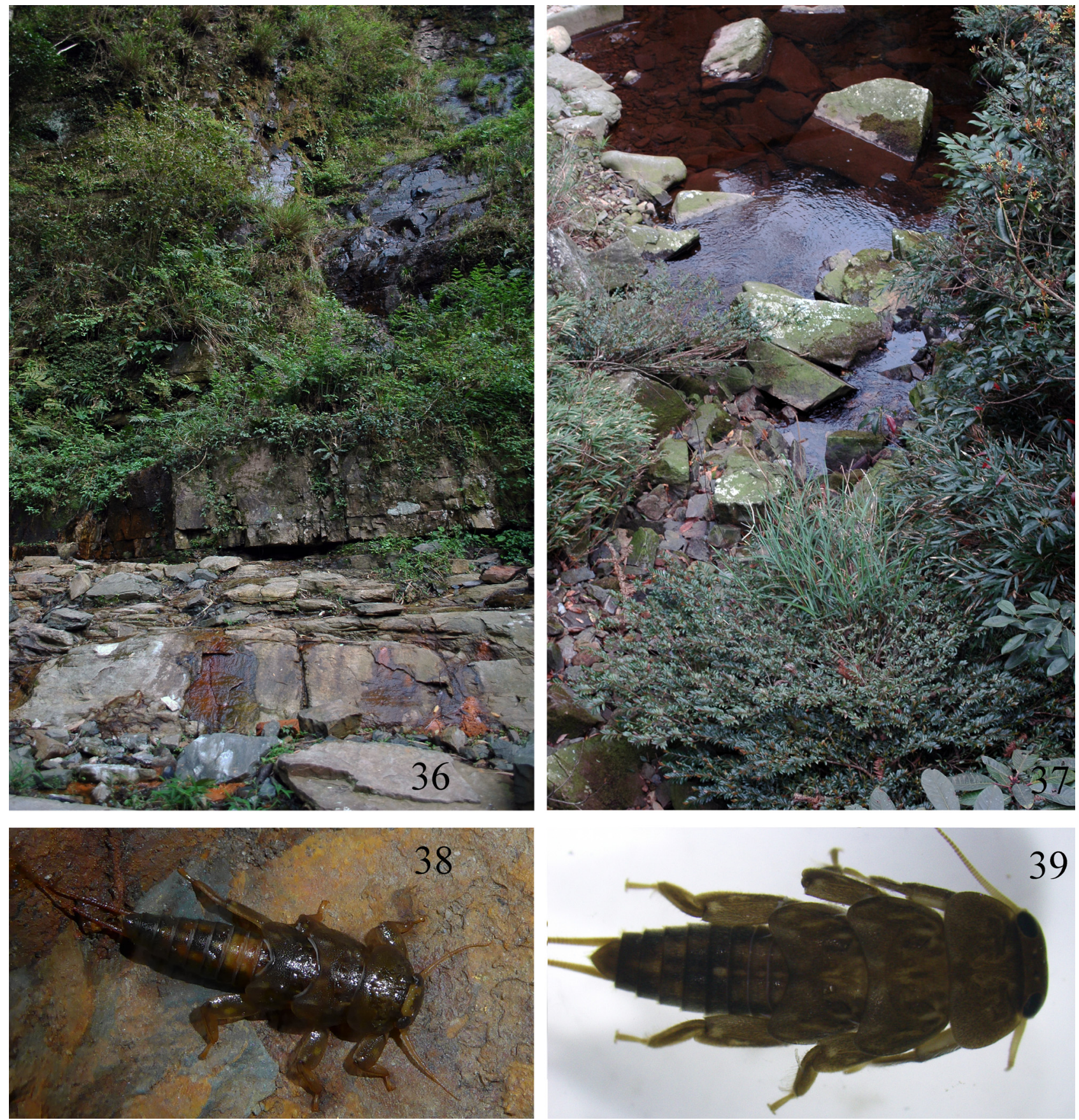

FIGURES 36-39. Cryptoperla teana Li \& Murányi, sp. n., habitats and larval habitus-36: seep at Golden Turtle Waterfall, locality of the holotype; 37: inflow stream above Dragon Lake, paratype locality; 38: alive pharate female larva at Golden Turtle Waterfall; 39: last instar but not matured larva from Dragon Lake, preserved in ethanol.

Distribution and ecology. The new species was found at two water flows within Damingshan National Natural Reserve, Guangxi Zhuang Autonomous Region. The Daming Mountains form relatively isolated range in central Guangxi, and the Cryptoperla was found on high plateau of the range. Lentic and lotic waters distinctively 'tea-colored' because of high humin acid content occurred. The two mature larvae were found under stones in a vertical rocky seep close to a pond beneath Golden Turtle Waterfall (Fig. 36), while penultimate instar larvae were numerous under littoral stones at rapid section of a stream flowing into Dragon Lake (Fig. 37). The matured larvae are both emerged safely within a few days; however, we were not able to rear the penultimate instar larvae from the Dragon Lake stream. March should be considered as beginning of the emergence period of the species. It is worth to note that penultimate instar larvae were able not only to run fast but to jump up to ten centimeters in distance. No mature eggs were found in the female adult despite being alive for more than two weeks. At the seep, the holotype 
and paratype were found together with numerous Indonemoura Baumann, 1975 larvae but no other stoneflies. The stream inhabited by the paratype larvae are shared with a few other Leuctridae, Nemouridae and Perlidae, including a new Rhopalopsole Klapálek, 1912 species (Li et al. 2017a).

Affinities. The female is difficult to identify, but combination of a broadly rounded subgenital plate, shape of metathoracal postscutellar process and general coloration distinguish it from most known congeners. The arrangement of setae of the male cerci is most similar to the Himalayan C. pentagonalis Zwick \& Sivec, 1980 and less to Central Chinese C. nangongshana Huo \& Du, 2018, but their figures (fig. 10, Huo \& Du 2018) of the everted aedeagi appear differ by more complex lobes and surface structures. No similar cerci or aedeagus were found after comparison with other Asian species (aedeagus of some Chinese species still unknown, e.g. even the lately described $C$. dactylina $\mathrm{Du}, 2018$ (in: Huo \& Du 2018)). The larva also appears similar to the $C$. pentagonalis by configuration of ventral fringes of thorax and dense blade-like setae of the cerci, but easy to distinguish on the basis of distinct color pattern.

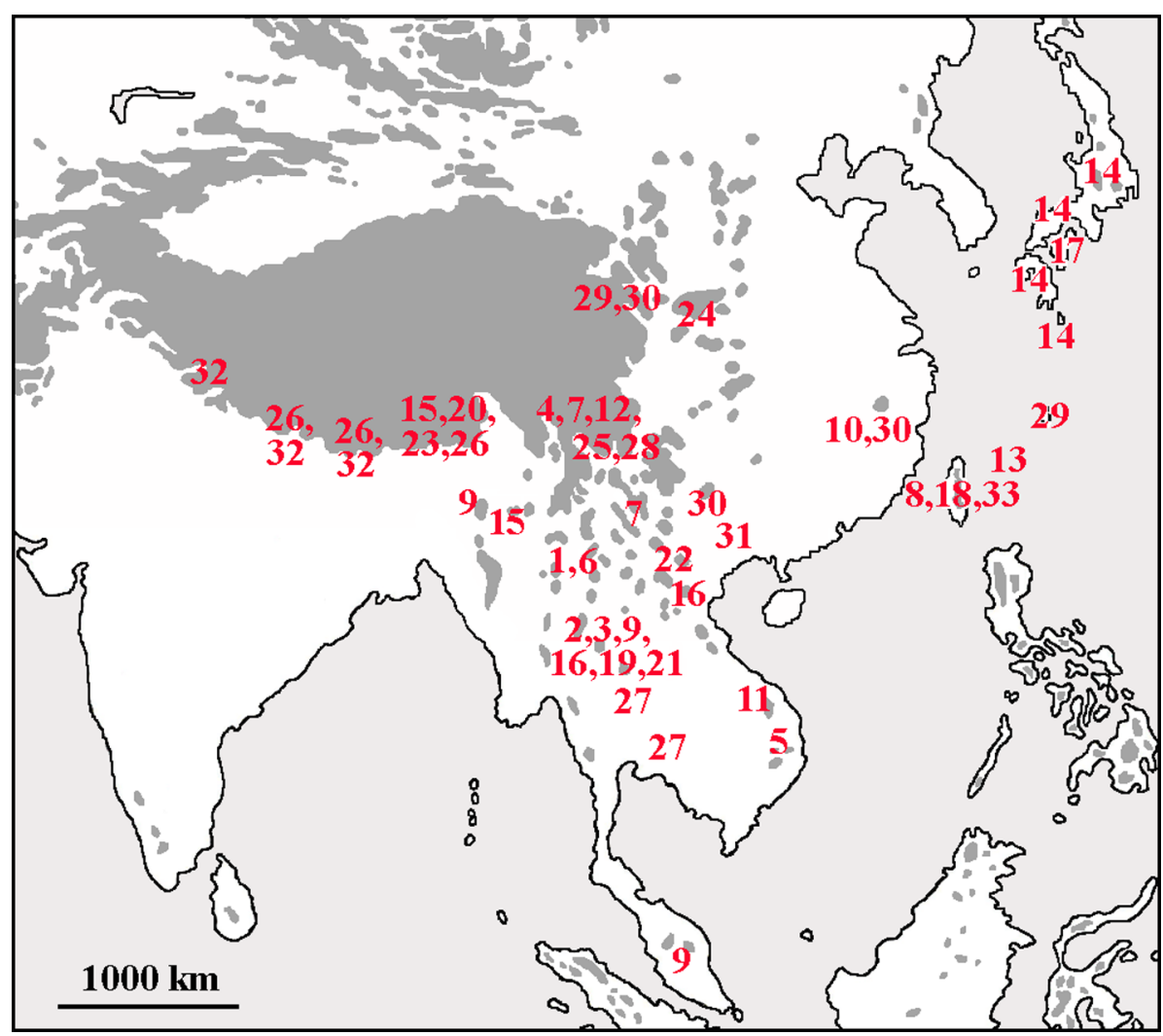

FIGURE 40. Known distribution of the Cryptoperla species-1: C. aculeata Wu, 1973); 2: C. akha Stark, 1989; 3: C. bisaeta (Kawai, 1968a); 4: C. chiangi (Banks, 1940); 5: C. curvata Stark \& Sivec, 2007a; 6: C. dactylina Du, 2018; 7: C. dui Sivec, 2005; 8: C. formosana (Okamoto, 1912); 9: C. fraterna (Banks, 1938); 10: C. fujianica Sivec, 1995; 11: C. hubleyi Stark \& Sivec, 2007a; 12: C. spec. Ch A sensu Stark \& Sivec, 2007a; 13: C. ishigakiensis (Kawai, 1968b); 14: C. japonica (Okamoto, 1912); 15: C. kali Stark, 1989; 16: C. karen Stark, 1989; 17: C. kawasawai Maruyama, 2002; 18: C. klapaleki Stark \& Sivec, 2007b; 19: C. kosai Stark \& Sivec, 2007a; 20: C. kumari Stark, 1989; 21: C. meo Stark, 1989; 22: C. meyi Stark \& Sivec, 2007a; 23: C. naga Stark, 1989; 24: C. nangongshana Huo \& Du, 2018; 25: C. obtusa (Wu, 1973); 26: C. pentagonalis Zwick \& Sivec, 1980; 27: C. simplex Stark \& Sivec, 2007a; 28: C. sinensis (Wu \& Claassen, 1934); 29: C. spp., unidentified; 30: $C$. stilifera Sivec, 1995; 31: C. teana sp. n.; 32: C. torva Needham, 1909; 33: C. uchidai Stark \& Sivec, 2007b-grey areas are above 2000 meters.

Etymology. The name teana (from the Latin word teanus, meaning 'of tea') refers to the habitat of the species, tea-colored waters of the Damingshan plateau. Used as a possessive pronoun, gender feminine.

Known distribution of the Cryptoperla species (Fig. 40). The genus Cryptoperla is distributed mainly in the eastern continental areas of the Oriental Region and enters the East Palaearctic on the Japanese Archipelago. No Cryptoperla species are known from the Indian Subcontinent outside of the Himalayas, neither from the Southeast Asian islands. The type species, C. torva Needham, 1909 and its type locality constitutes the westernmost occurrence, in Himachal Pradesh state of India. Cryptoperla torva and C. pentagonalis Zwick \& Sivec, 1980 seem 
to be widespread in most of the Himalayas, whereas the further three species were found in the East Himalayas, in Arunachal Pradesh state of India. The Tibetan Plateau and the Indochina Peninsula apparently is the center of species diversity of the genus, with the northernmost continental records known from southern Gansu Province of China (C. stilifera Sivec, 1995). The genus apparently dispersed southwards into peninsular Malaysia (C. fraterna (Banks, 1938)). In the eastern areas of Oriental China, the genus seems to be rare, with only two species known from Fujian Province (C. fujianica Sivec, 1995 and C. stilifera Sivec, 1995). East of the continent, Cryptoperla species occur on Taiwan, larger isles of the Ryukyus, Kyushu, Shikoku and on Honshu up to Nagano Prefecture of Japan.

\section{Acknowledgements}

We are very indebted to Dr. Guoquan Wang (Guangxi University) for the assistance during the collecting trip and also for Dr. Jenő Kontschan (Hungarian Academy of Sciences) and Mr. Junyi Li, Ms. Shan Li (HIST) for taking part in field work. We acknowledge the support of our research by Aid program for Science and Technology Innovative Research Team in higher Educational Institutions of Henan Province (17IRTSTHN18), the National Natural Science Foundation of China (No. 31372251), the landmark Innovative Project of Institute of Science and Technology (No. 2015BZ04) and the 2013-2015 Sino-Hungarian scientific and technological cooperative projects (No. 6-33 in China, TÉT_12_CN-1-2012-0006 in Hungary).

\section{References}

Banks, N. (1938) XXI. Further neuropteroid insects from Malaya. Journal of the Federated Malay States Museums, 18, 220235.

Banks, N. (1940) Report on certain groups of neuropteroid insects from Szechwan, China. Proceedings of the United States National Museum, 88, 173-220. https://doi.org/10.5479/si.00963801.88-3079.173

DeWalt, R.E., Maehr, M.D., Neu-Becker, U. \& Stueber, G. (2018) Plecoptera Species File Online. Version 5.0/5.0. Available from: http://Plecoptera.Species.File.org (accessed 9 May 2018)

Du, Y.Z. \& Sivec, I. (2005) Plecoptera. In: Yang, X.K. (Ed.), Insect Fauna of Middle-west Qinling Range and South Mountains of Gansu Province. Science Press, Beijing, pp. 38-54.

Huo, Q.B. \& Du, Y.Z. (2018) Two new species of Cryptoperla (Plecoptera, Peltoperlidae) from China. Zootaxa, 4374 (3), 395 408.

Huo, Q.B., Du, Y.Z. \& Yuan, D. (2017) First record of the genus Soliperla (Plecoptera: Peltoperlidae) from China with description of a new species. Zootaxa, 4362 (4), 589-600.

https://doi.org/10.11646/zootaxa.4362.4.8

Kato, Y., Morii, Y. \& Tojo, K. (2013) Molecular phylogeographic analysis of East Asian cryptoperlan stoneflies (Insecta: Plecoptera, Peltoperlidae). Limnology, 14 (2), 179-194. https://doi.org/10.1007/s10201-012-0395-3

Kawai, T. (1968a) Stoneflies (Plecoptera) from Thailand and India with descriptions of one new genus and two new species. Oriental Insects, 2, 107-139.

Kawai, T. (1968b) Stoneflies (Plecoptera) from the Ryukyu Islands in the Bishop Museum, Honolulu. Pacific Insects, 10, 231239.

Klapálek, F. (1913) Plecoptera II. In: H Sautr's Formosa-Ausbeute. Supplementa Entomologica, 2, pp. 112-127.

Kontschán, J., Wang, G.Q. \& Neményi A. (2015) Nenteria lii sp. n. (Acari: Mesostigmata: Nenteriidae) a new bamboo leaf litter dwelling Uropodina species (Acari: Mesostigmata) from Xinxiang (Henan, China) with notes to the bamboo associated mites in Henan (China). Acta Phytopathologica et Entomologica Hungarica, 50 (2), 195-208.

Li W.H., Murányi, D., Gamboa, M., Yang, D. \& Watanabe, K. (2017a) New species and records of Leuctridae (Plecoptera) from Guangxi, China, on the basis of morphological and molecular data, with emphasis on Rhopalopsole. Zootaxa, 4243 (1), 165-176.

Li W.H., Murányi, D., Orci, K.M., Uchida S. \& Wang, R.F. (2017b) A new species of Sinacroneuria (Plecoptera: Perlidae) from Guangxi Zhuang Autonomous Region, southcentral China based on male adult, larva and drumming signals, and validation of the Japanese species of the genus. Zootaxa, 4299 (1), 095-108.

Maruyama, H. (2002) A new species of the genus Cryptoperla (Plecoptera, Peltoperlidae) from Japan. Japanese Journal of Systematic Entomology, 8, 1-6.

Needham, J.G. (1909) Notes on the Neuroptera in the collection of the Indiana Museum. Records of the Indian Museum, 3 (12), 
185-210, pls. XIX-XXI.

Okamoto, H. (1912) Ersten Beitrag zur Kenntnis der Japanischen Plecopteren. Transactions of the Sapporo Natural History Society, 4, 105-170.

Ricker, W.E. (1952) Systematic studies in Plecoptera. Indiana University Publications, Science Series, 18, 1-200.

Sivec, I. (1995) Cryptoperla fujianica spec. nov., and Cryptoperla stilifera spec. nov., two new Peltoperlidae species from Fujian, China (Plecoptera). Opuscula Zoologica Fluminensia, 132, 1-5.

Sivec, I. (2005) Cryptoperla dui, sp. n., a new stonefly from South China (Plecoptera: Peltoperlidae). Illiesia, 1, 8-9.

Stark, B.P. (1989) Oriental Peltoperlinae (Plecoptera): A generic review and descriptions of a new genus and seven new species. Entomologica Scandinavica, 19, 503-525. https://doi.org/10.1163/187631289X00609

Stark, B.P. \& Sivec, I. (2007a) New species and records of Asian Peltoperlidae (Insecta: Plecoptera). Illiesia, 3 (12), $104-126$.

Stark, B.P. \& Sivec, I. (2007b) Taiwanese species of Cryptoperla (Plecoptera: Peltoperlidae). Illiesia, 3 (14), $150-156$.

Uchida, S. \& Isobe, Y. (1988) Cryptoperla and Yoraperla from Japan and Taiwan (Plecoptera: Peltoperlidae). Aquatic Insects, 10, 17-31. https://doi.org/10.1080/01650428809361306

Wu, C.F. (1973) New species of Chinese stoneflies (Order Plecoptera). Acta Entomologica Sinica, 16, 97-118.

Wu, C.F. \& Claassen, P.W. (1934) Aquatic insects of China. 18. New species of Chinese stoneflies (Order Plecoptera). Peking Natural History Bulletin, 9, 111-129.

Zwick, P. (1977) Ergebnisse der Bhutan-Expedition 1972 des Naturhistorischen Museums in Basel Plecoptera. Entomologica Basiliensia, 2, 85-134.

Zwick, P. \& Sivec, I. (1980) Beiträge zur Kenntnis der Plecoptera des Himalaja. Entomologica Basiliensia, 5, 59-138. 